\title{
Performance Analysis of modulation techniques for Induction motor fed by Diode-Clamped NPC Inverter
}

\author{
Sejal Singh $^{\# 1}$, SudhanshuTripathi ${ }^{* 2}$ \\ ${ }^{\#}$ M.Tech.Scholar\&Department of Electrical and Electronics Engineering Sam Higginbottom Institute of \\ Agriculture Technology \& SciencesAllahabad, India
}

\begin{abstract}
This paper presents speed control of induction motor fed by Neutral Point Clamped voltage source inverter. The NPC inverter produces fewer harmonic than the other type of inverter. This shows the advantageover conventional VSI. For this result, comparison is made between the sinusoidal pulse width modulation and space vector pulse width modulation. From the analysis of the total harmonic distortion (THD) in the current of inverter the space vector pulse width modulation (SVPWM) was found more superior than sinusoidal pulse width modulation (SPWM). Simulation results are also presented to show the effectiveness of the proposed system.
\end{abstract}

Keywords:Neutral Point Clamped Inverter, Sinusoidal Pulse Width Modulation, Space Vector Modulation, THD

\section{Introduction}

The voltage source inverter produce an output voltage or a current with levels either 0 or $\pm V_{\mathrm{dc}}$. They are known as two level inverters. To obtain a quality output voltage or a current waveform with a minimum amount of ripple content, they require high switching frequency along with various pulse width modulation (PWM) strategies.

The multilevel inverters have drawn tremendous interest in the power industry. They present a new set of features that are well suited for use in reactive power compensation. It may be easier to produce a high power, high voltage inverter with the multilevel structure because of the way in which device voltage stresses are controlled in the structure.For the NPC inverters, a variety of modulation strategies have been reported, with the most popular being carrier-based pulse-width modulation (SPWM), space vector modulation (SVPWM)NPC inverters halves the maximum drop voltage on their devices because they are builtup of four switches per phase, furnish a three-level voltage output and improve the current tracking performances in current control loops; moreover, they present a better harmonic content of the current than traditional VSI, allowing a torque ripple reduction.

The speed of three phase induction motor fed by the three level neutral point clamped inverter is shown by the following block diagram (fig.1).

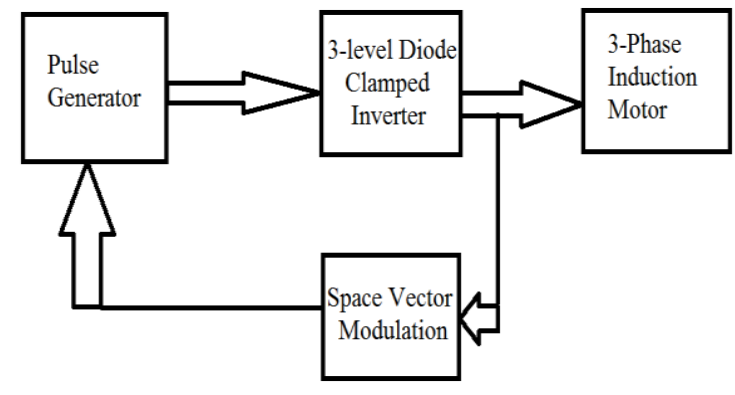

Fig.1

II. Pulse Width Modulation in Inverter

In the PWM method a fixed dc voltage is applied to the inverter and a controlled ac voltage is achieved by switching on and off of the switching devices.

As in 3-level NPC inverter, modulation strategies can be framed into two main techniques:

a) Sinusoidal Pulse width Modulation technique

b)Space Vector Modulation technique 
a) Sinusoidal Pulse width Modulation technique:

In the case of sinusoidal pulse width modulation the width of each pulse is varied in proportion to the amplitude of a sine wave. In this technique the gatingsignals are generated by comparing a sinusoidal reference signal with a triangular carrier wave.
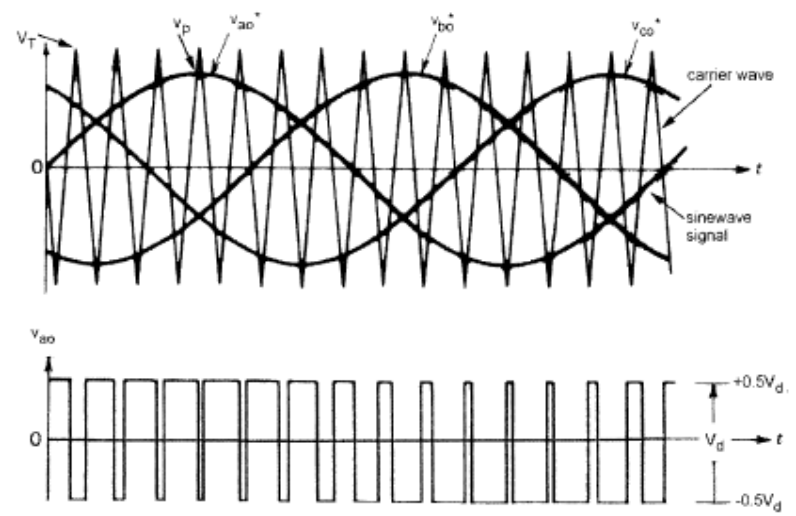

Fig.2 Principle of sinusoidal pulse width modulation

\section{b) Space Vector Modulation technique}

The space vector modulation is an advanced technique of pulse width modulation and we can say that this technique is possibly the best technique among the other modulation techniques which are used in the adjustable speed drive system. There are some important points about the space vector modulation technique:

1) The SVM technique treats the sinusoidal voltage as a constant amplitude vector rotating at constant frequency.

2) This technique approximates the reference voltage $V_{\text {ref }}$ by a combination of the eight switching patterns $\left(V_{0}\right.$ to $\mathrm{V}_{7}$ ).

The possible eight switching patterns are listed in the table A:

\begin{tabular}{|c|c|c|c|c|c|c|c|c|c|c|}
\hline Vector & $\mathbf{A}^{+}$ & $\mathbf{B}^{+}$ & $\mathbf{C}^{+}$ & $\mathbf{A}^{-}$ & $\mathbf{B}^{-}$ & $\mathrm{C}^{-}$ & $\mathbf{V}_{\mathrm{AB}}$ & $\mathbf{V}_{\mathrm{BC}}$ & $\mathbf{V}_{\mathrm{CA}}$ & \\
\hline $\begin{array}{c}\mathrm{V}_{0}= \\
\{000\}\end{array}$ & OFF & OFF & OFF & ON & $\mathrm{ON}$ & ON & 0 & 0 & 0 & $\begin{array}{c}\text { zero } \\
\text { vector }\end{array}$ \\
\hline $\begin{array}{c}\mathrm{V}_{1}= \\
\{100\}\end{array}$ & $\mathrm{ON}$ & OFF & OFF & OFF & $\mathrm{ON}$ & ON & $+\mathrm{V}_{\mathrm{dc}}$ & 0 & $-\mathrm{V}_{\mathrm{dc}}$ & $\begin{array}{l}\text { active } \\
\text { vector }\end{array}$ \\
\hline $\begin{array}{c}V_{2}= \\
\{110\}\end{array}$ & ON & ON & OFF & OFF & OFF & ON & 0 & $+\mathrm{V}_{\mathrm{dc}}$ & $-\mathrm{V}_{\mathrm{dc}}$ & $\begin{array}{l}\text { active } \\
\text { vector }\end{array}$ \\
\hline $\begin{array}{c}\mathrm{V}_{3}= \\
\{010\}\end{array}$ & OFF & ON & OFF & ON & OFF & ON & $-\mathrm{V}_{\mathrm{dc}}$ & $+\mathrm{V}_{\mathrm{dc}}$ & 0 & $\begin{array}{l}\text { active } \\
\text { vector }\end{array}$ \\
\hline $\begin{array}{c}\mathrm{V}_{4}= \\
\{011\}\end{array}$ & OFF & ON & ON & ON & OFF & OFF & $-\mathrm{V}_{\mathrm{dc}}$ & 0 & $+\mathrm{V}_{\mathrm{dc}}$ & $\begin{array}{l}\text { active } \\
\text { vector }\end{array}$ \\
\hline $\begin{array}{c}V_{5}= \\
\{001\}\end{array}$ & OFF & OFF & ON & ON & ON & OFF & 0 & $-\mathrm{V}_{\mathrm{dc}}$ & $+\mathrm{V}_{\mathrm{dc}}$ & $\begin{array}{l}\text { active } \\
\text { vector }\end{array}$ \\
\hline $\begin{array}{c}\mathrm{V}_{6}= \\
\{101\}\end{array}$ & ON & OFF & $\mathrm{ON}$ & OFF & $\mathrm{ON}$ & OFF & $+\mathrm{V}_{\mathrm{dc}}$ & $-\mathrm{V}_{\mathrm{dc}}$ & 0 & $\begin{array}{l}\text { active } \\
\text { vector }\end{array}$ \\
\hline $\begin{array}{c}\mathrm{V}_{7}= \\
\{111\}\end{array}$ & ON & ON & ON & OFF & OFF & OFF & 0 & 0 & 0 & $\begin{array}{c}\text { zero } \\
\text { vector }\end{array}$ \\
\hline
\end{tabular}

Table.(A)

In the space vector modulation technique the desired three phase output voltage of this equivalent voltage vector is related to the magnitude of the voltage vector and this vector takes the same time as the fundamental time period to complete one rotation. This can be represented by an equivalent voltage vector which is rotating in the counter clockwise direction. This can be represented by the following fig. 3 


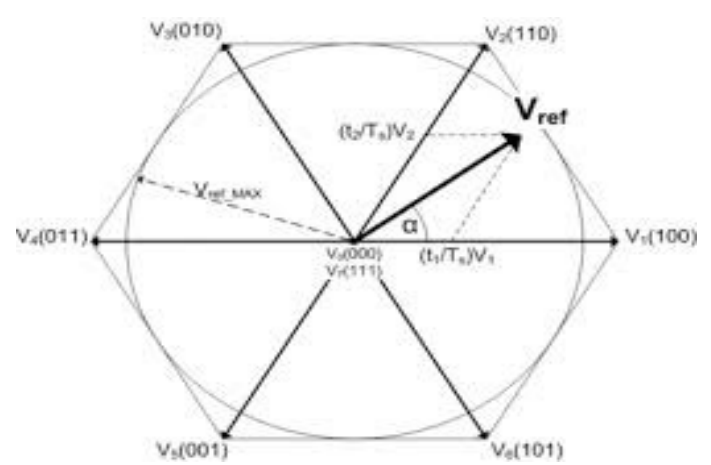

Fig.3 space vector representation

For the implementation of the space vector modulation the reference signal $\left(\mathrm{V}_{\text {ref }}\right)$ is sampled with a frequency $\left(f_{s}\right)$. This reference signal may be generated from the three separate phase references with the use of $\alpha \beta \gamma$ transformation. This reference vector is then synthesized using the combination of two neighbouring active switching vectors and oneor both of the zero vectors. For the selection of the order of the vectors and with zero vectors various strategies are used. The selection of strategy willaffect the harmonic content and the switching losses of the inverter. With the use of the space vector modulation there are eight possible switching vectors in a three leg inverter.

\section{I) Reference Vector}

Thereference voltage vector $V_{\text {ref }}$ is representedina $\alpha \beta$-plane.The $\alpha \beta$-plane isatwo-dimensionalplane which istransformedfrom a three-dimensional plane containingthevectorsofthethreephases and theswitchesbeingONor OFF is determined bythe locationof the referencevector $\mathrm{V}_{\text {ref }}$ on this $\alpha \beta$-plane.

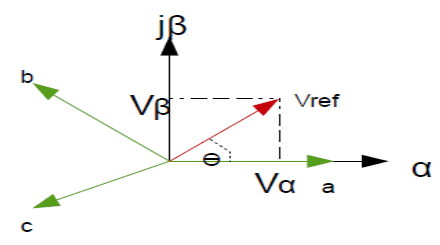

Fig.4 representation of the reference vector in the two and three dimensionalplane

Table A shows that the switches can be ON or OFF, meaning 1 or 0 . The switches 1, 3, 5 are the upper switches and if these are 1 (separately or together) it turns the upper inverter leg ON and the terminal voltage $\left(\mathrm{Va}, \mathrm{Vb}, \mathrm{V}_{\mathrm{c}}\right)$ is positive $(+\mathrm{Vdc})$. If the upper switches are zero, then the terminal voltage is zero.

\section{ii) DETERMINE $\mathbf{V}_{\mathrm{d}}, \mathbf{V}_{\mathrm{q}}, \mathbf{V}_{\text {ref }}$}

$$
\begin{aligned}
& \mathrm{V}=\mathrm{V}_{\alpha}+j \mathrm{~V}_{\beta} \\
& =2 / 3\left(\mathrm{~V}_{\alpha}+\alpha \mathrm{V}_{\mathrm{b}}+\alpha^{2} \mathrm{~V}_{\mathrm{c}}\right)
\end{aligned}
$$

Where $\mathrm{a}=\mathrm{e}^{\mathrm{j} 2 \Pi / 3}$

$\mathrm{V}=\sqrt{ }\left(\mathrm{V}_{\alpha}{ }^{2}+\mathrm{V}_{\beta}{ }^{2}\right), \alpha=\tan ^{-1}\left(\frac{\mathrm{V}_{\beta}}{\mathrm{V}_{\alpha}}\right)(2)$

$\mathrm{V}_{\mathrm{a}}+\mathrm{j} \mathrm{V}_{\beta}=\frac{2}{3}\left(\mathrm{~V}_{\mathrm{a}}+\mathrm{e}^{\mathrm{j} 2 \Pi / 3} \mathrm{~V}_{\mathrm{b}}+\mathrm{e}^{-\mathrm{j} 2 \Pi / 3} \mathrm{~V}_{\mathrm{c}}\right)(3)$

$\mathrm{V}_{\mathrm{a}}+\mathrm{j} \mathrm{V}_{\beta}=\frac{2}{3}\left(\mathrm{~V}_{\mathrm{a}}+\cos \frac{2 \Pi}{3} \mathrm{~V}_{\mathrm{b}}+\cos \frac{2 \Pi}{3} \mathrm{~V}_{\mathrm{c}}\right)+\mathrm{j} \frac{2}{3}\left(\sin \frac{2 \Pi}{3} \mathrm{~V}_{\mathrm{b}}-\sin \frac{2 \Pi}{3} \mathrm{~V}_{\mathrm{c}}\right)$

Equating real and imaginary part

$\mathrm{V}_{\mathrm{a}}=\frac{2}{3}\left(\mathrm{~V}_{\mathrm{a}}+\cos \frac{2 \Pi}{3} \mathrm{~V}_{\mathrm{b}}+\cos \frac{2 \Pi}{3} \mathrm{~V}_{\mathrm{c}}\right)$

$\mathrm{V}_{\beta}=\mathrm{j}_{3}^{\frac{2}{3}}\left(\mathrm{~V}_{\mathrm{a}}+\sin \frac{2 \Pi}{3} \mathrm{~V}_{\mathrm{b}}-\sin \frac{2 \Pi}{3} \mathrm{~V}_{\mathrm{c}}\right)$

$\left[\begin{array}{c}\mathrm{V}_{\alpha} \\ \mathrm{V}_{\beta}\end{array}\right]=\frac{2}{3}\left[\begin{array}{ccc}1 & \cos \frac{2 \Pi}{3} & \cos \frac{2 \pi}{3} \\ 0 & \sin \frac{2 \Pi}{3} & -\sin \frac{2 \pi}{3}\end{array}\right]\left[\begin{array}{l}\mathrm{V}_{\mathrm{a}} \\ \mathrm{V}_{\mathrm{b}} \\ \mathrm{V}_{\mathrm{c}}\end{array}\right]$ (7)

$\left[\begin{array}{c}\mathrm{V}_{\alpha} \\ \mathrm{V}_{\beta}\end{array}\right]=\frac{2}{3}\left[\begin{array}{ccc}1 & -0.5 & -0.5 \\ 0 & \sqrt{3} / 2 & -\sqrt{3} / 2\end{array}\right]\left[\begin{array}{l}\mathrm{V}_{\mathrm{a}} \\ \mathrm{V}_{\mathrm{b}} \\ \mathrm{V}_{\mathrm{c}}\end{array}\right]$ (8)

$\mathrm{V}_{\mathrm{d}}=\mathrm{V}_{\alpha}, \mathrm{V}_{\mathrm{q}}=\mathrm{V}_{\beta}$ 
iii)DETERMINATION TIME DURATION $\mathrm{T}_{1}, \mathrm{~T}_{2}, \mathrm{~T}_{0}$

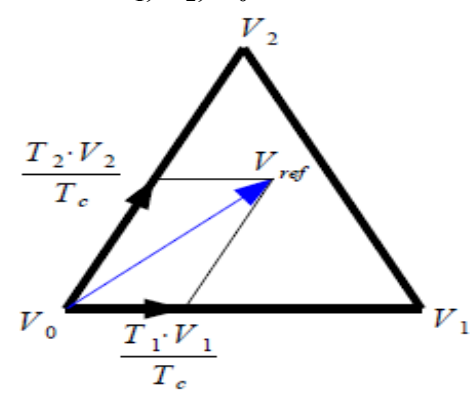

Fig. 5 Reference vector as a combination of adjacent vectors at sector-1

$\mathrm{T}_{1}=\mathrm{T}_{\mathrm{Z}} \cdot \mathrm{a} \cdot \frac{\sin \left(\frac{\mathrm{T}}{3}-\alpha\right)}{\sin \left(\frac{\pi}{(\pi / 3)}\right.}$

$\mathrm{T}_{2}=\mathrm{T}_{\mathrm{z}} \cdot \mathrm{a} \cdot \frac{\sin (\dot{(\alpha)})}{\sin (\mathrm{(II} / 3)}$

$\mathrm{T}_{0}=\mathrm{T}_{\mathrm{z}}-\left(\mathrm{T}_{1}+\mathrm{T}_{2}\right)$, where, $\mathrm{T}_{\mathrm{z}}=\frac{1}{\mathrm{f}_{\mathrm{s}}}$ and $\mathrm{a}=\frac{\left|\mathrm{V}_{\mathrm{ref}}\right|}{\frac{2}{3} \mathrm{~V}_{\mathrm{dc}}}$

Where $T_{1}, T_{2}, T_{0}$ represent the time widths for vectors $V_{1}, V_{2}, V_{0} . T_{0}$ is the period in a sampling period for null vectors should be filled. As each switching period (half of sampling period) $T_{z}$ starts and ends with zero vectors i.e there will be two zero vectors per $T_{z}$ or four null vectors per $T_{s}$, duration of each null vector is $\mathrm{To} / 4$.

\subsection{Switching Time Duration Of Any Sector}

$\mathrm{T}_{1}=\frac{\sqrt{3} \cdot \mathrm{T}_{\mathrm{z}} \cdot \mathrm{V}_{\mathrm{ref}} \mathrm{I}}{\mathrm{V}_{\mathrm{dc}}}\left(\sin \left(\frac{\Pi}{3}-\alpha+\frac{\mathrm{n}-1}{3} \Pi\right)\right)$

$=\frac{\sqrt{3} \cdot \mathrm{T}_{\mathrm{Z}} \cdot \mid \mathrm{V}_{\mathrm{ref}} \mathrm{I}}{\mathrm{V}_{\mathrm{dc}}}\left(\sin \left(\frac{\Pi}{3}-\alpha\right)\right)$

$=\frac{\sqrt{3} \cdot T_{\mathrm{z}} \cdot \mathrm{V}_{\mathrm{ref}} \mid}{\mathrm{V}_{\mathrm{dc}}}\left(\sin \frac{\mathrm{n} \Pi}{3} \cdot \cos \alpha-\cos \frac{\mathrm{n} \Pi}{3} \cdot \sin \alpha\right) \&$

$\mathrm{T}_{2}=\frac{\sqrt{3} \cdot \mathrm{T}_{\mathrm{z}} \cdot \mid \mathrm{V}_{\mathrm{ref}} \mathrm{I}}{\mathrm{V}_{\mathrm{dc}}}\left(\sin \left(\alpha-\frac{\mathrm{n}-1}{3} \Pi\right)\right)$

$=\frac{\sqrt{3} \cdot T_{\mathrm{z}} \cdot \mathrm{V}_{\mathrm{ref}} \mid}{\mathrm{V}_{\mathrm{dc}}}\left(\sin \alpha \cdot \cos \frac{\mathrm{n}-1}{3} \Pi-\cos \alpha \cdot \sin \frac{\mathrm{n}-1}{3} \Pi\right) \&$

$\mathrm{T}_{0}=\mathrm{T}_{\mathrm{z}}-\left(\mathrm{T}_{1}+\mathrm{T}_{2}\right)$; Where, $\mathrm{n}=1$ to 6 (That is sector 1 to 6 ) and $0 \leq \alpha \leq 60^{\circ}$

\section{NPC Inverter Equivalent Circuit and Operating Principle}

The neutral point clamped inverter is one of the most widely used multilevel structures. This structure was first proposed by Nabaeet. al in 1980. The equivalent circuit of NPC-source inverter is shown in Fig.6

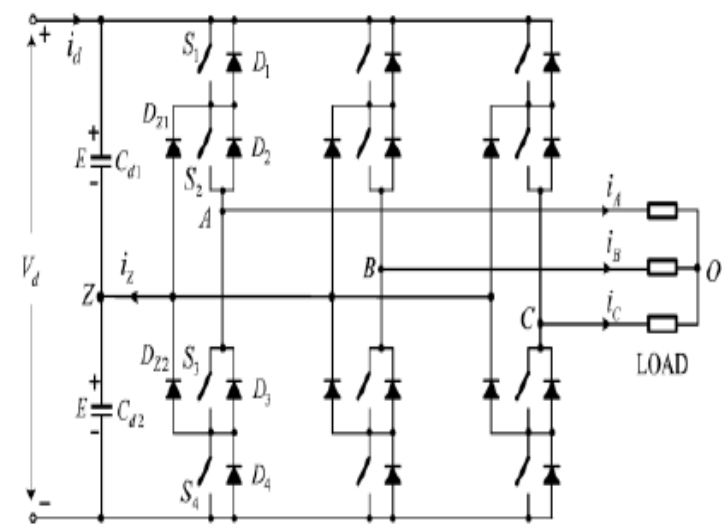

Fig.6.Three level Neutral-Point-Clamped inverter 


\section{Principle of Operation}

To produce a staircase output voltage, let us consider only one leg of 3 level inverter. The dc rail 0 is the reference point of the output phase voltage. The steps to synthesize the five level voltages are as follows:

1. For an output voltage level $\mathrm{v}_{\mathrm{ao}}=\mathrm{V}_{\mathrm{dc}}$, turn on all upper-half switches $\mathrm{S}_{\mathrm{a} 1}$ through $\mathrm{S}_{\mathrm{a} 4}$.

2. For an output voltage level $\mathrm{v}_{\mathrm{ao}}=3 \mathrm{~V}_{\mathrm{dd}} / 4$, turn on three upper-half switches $\mathrm{S}_{\mathrm{a} 2}$ through $\mathrm{S}_{\mathrm{a} 4}$ and one lower switch $\mathrm{S}_{\mathrm{a} 1} .77$

3. For an output voltage level $\mathrm{v}_{\mathrm{ao}}=\mathrm{V}_{\mathrm{dd}} / 2$, turn on two upper-half switches $\mathrm{S}_{\mathrm{a} 3}$ through $\mathrm{S}_{\mathrm{a} 4}$ and two lower switches $\mathrm{S}_{\mathrm{a} 1}$ and $\mathrm{S}_{\mathrm{a} 2}$.

4. For an output voltage level $\mathrm{V}_{\mathrm{a} o}=\mathrm{V}_{\mathrm{dc}} / 4$, turn on one upper-half switches $\mathrm{S}_{\mathrm{a} 4}$ and three lower switches $\mathrm{S}_{\mathrm{a} 1}$ through $\mathrm{S}_{\mathrm{a} 3 \text {. }}$.

5. For an output voltage level $\mathrm{Va} 0=0$, turn on all the upper half switches $\mathrm{S}_{\mathrm{a} 1}$ through $\mathrm{S}_{\mathrm{a} 4}$.

\section{Simulation Result and Discussion}

The simulation tests were performed taking into account a Field Oriented Controlled drive employing a neutral point clamped inverter and induction motor of rating $5 \mathrm{HP}, 460 \mathrm{~V}, 50 \mathrm{~Hz}$ at different torque input.

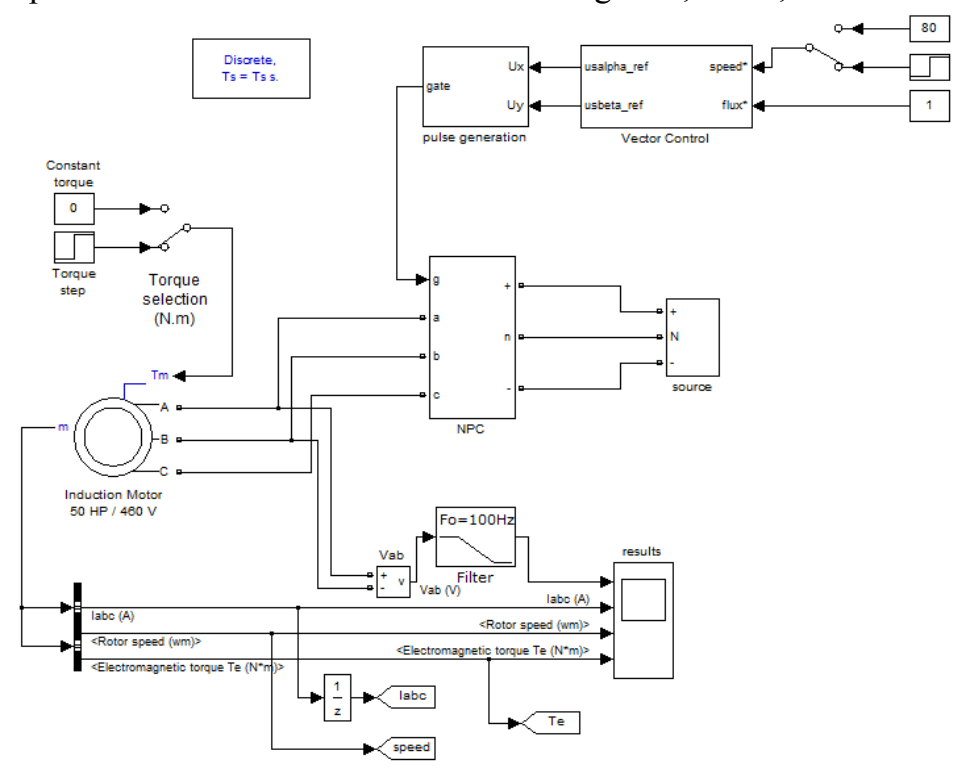

Fig.7

Speed control of the induction motor is applied here for the various operating condition such as following:

a) Constant torque and constant speed condition

b) Constant torque and variable speed condition

c) Variable torque and constant speed condition

d) Variable torque and variable Speed condition

Conditions for the Constant torque and variable speed condition and Variable torque and variable Speed condition are discussed here:

\section{Constant Torque \&and Variable Torque} (a) and (b).

For this condition we select a constant value of torque and a constant value of speed as shown in figure
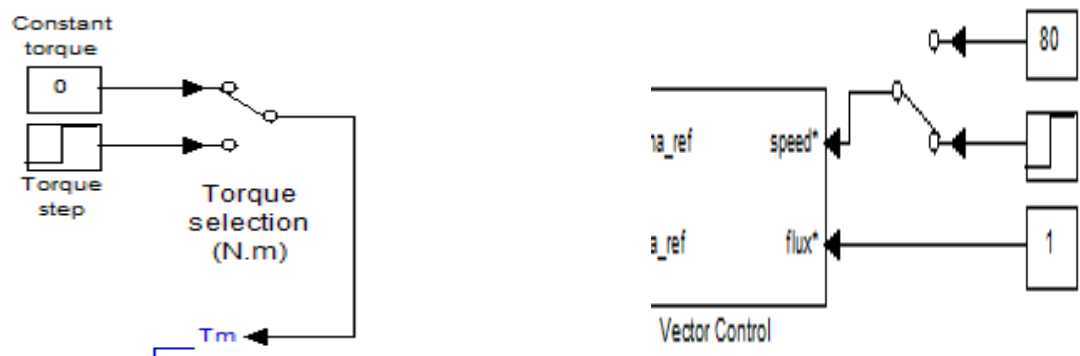

(a) Constant Torque selection(b)Constant speed selection

Fig. 8 


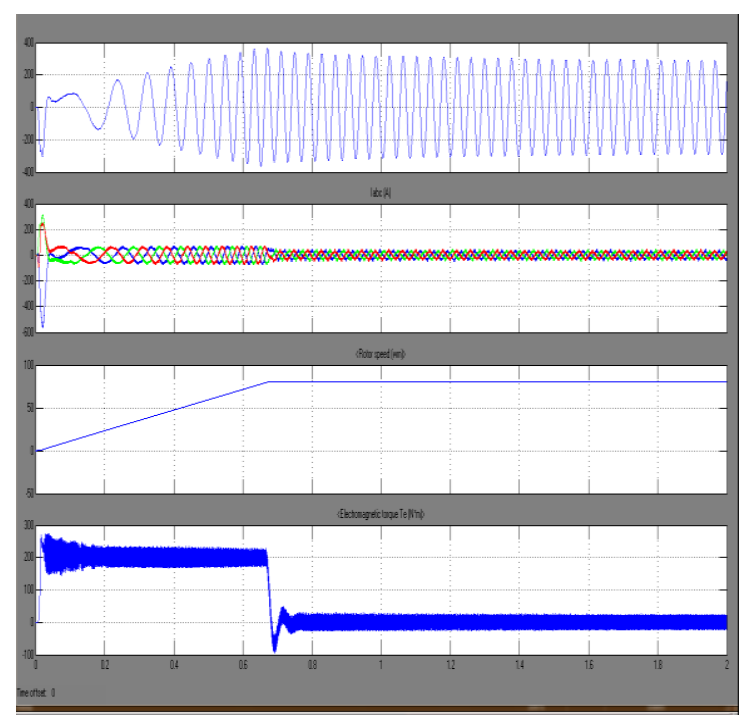

Fig 9 Result for Constant torque and constant Speed condition

The response of the result is as shown in fig9. It is clear that initially during transient period the torque contains an average value of $200 \mathrm{~N}-\mathrm{m}$ at and the value of rotor speed goes on increasing from $0 \mathrm{rad}-\mathrm{s}^{-1}$ to $80 \mathrm{rad}-\mathrm{s}^{-1}$. At the instant at which speed reaches the selected value $\left(=80 \mathrm{rad}_{-}^{-1}\right)$ system inters in steady state conditions and waveforms of currents goes on smooth. At this instant after some fluctuations the value of torque reaches its selected value.

\section{Variable Torque and Variable Speed Condition}

In such condition the operation is taken place for a variable value of torque and variable speed. The fig (a) and (b) shows the condition for such case, here we select the variable torque values whereas speed selected as constant value.
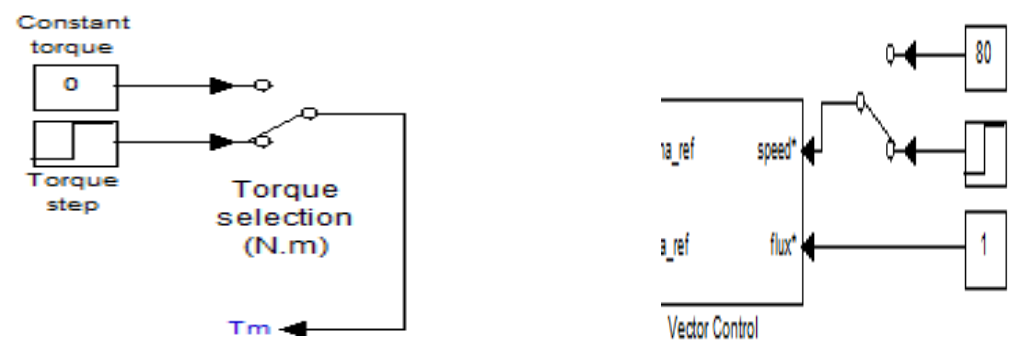

(a)Variable Torque selection(b) Variable speed selection

Fig. 10

The response of the result is as shown in fig 10.It is clear that initially during transient period the torque contains an average value of $200 \mathrm{~N}-\mathrm{m}$ at and the value of rotor speed goes on increasing from 0 rad $-\mathrm{s}^{-1}$ to $80 \mathrm{rad}_{-1}^{-1}$ (as its selected initial value). At the instant at which speed reaches the selected value $\left(=80 \mathrm{rad}-\mathrm{s}^{-1}\right)$ system inters in steady state conditions and waveforms of currents goes on smooth.

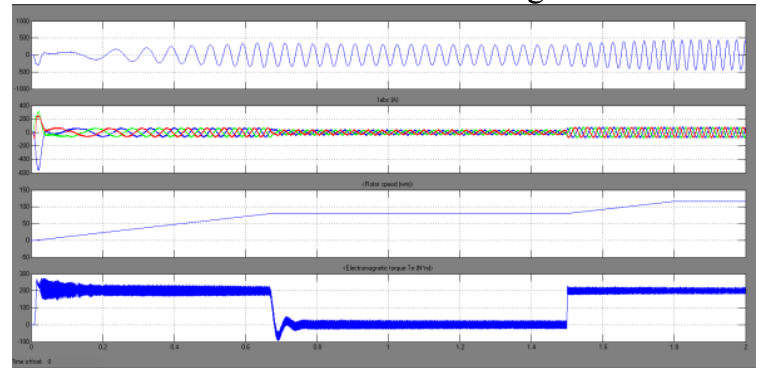

Fig11. Result for variable torque and variable Speed condition

At this instant after some fluctuations the value of torque reaches its selected value $(=0 \mathrm{~N}-\mathrm{m})$. As we select the step time $1.8 \mathrm{~s}$ is for torque and final value of the torque as $200 \mathrm{~N}-\mathrm{m}$. The step time is selected for speed variation is as $1.5 \mathrm{~s}$ so at this instant the value of speed again goes on increasing (from 80 $\mathrm{rad}^{-1} \mathrm{~s}^{-1}$ to 140 $\mathrm{rad}^{-\mathrm{s}^{-1}}$ ) 


\section{Output of 3-Level NPC Inverter}

Output of the three levels NPC inverter is shown in fig.12

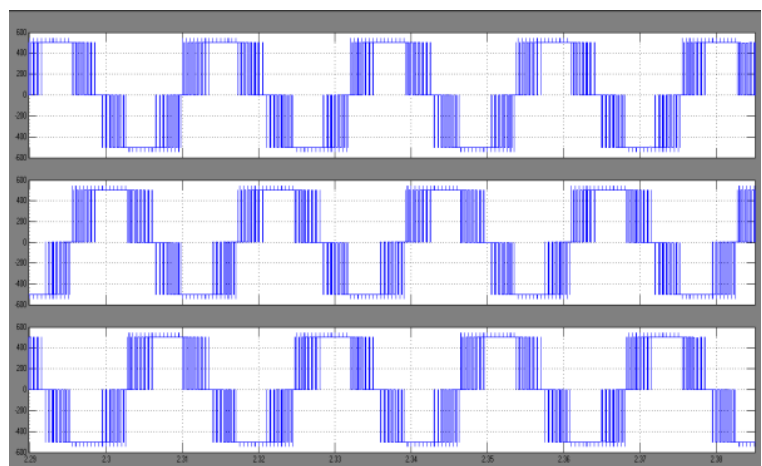

Fig.12

\section{Conclusion}

This paper presented the Performance Comparisons of Modulation Technique for Induction Motor fed by Diode-Clamped Neutral-Point-Clamped Inverter. The proposed space vector method, using single carrier instead of multi carriers, together with pulse decode, provided an effective pulse-control method for the diodeclamped NPC inverter. The study describes three different modulation techniques, suitable for NPC inverters supplying an induction motor, and exhibits a comparison between them, taking into account the harmonics introduce on the motor stator current. The first modulation technique is the classical Sinusoidal PWM, adapted to a NPC inverter employing a suitable selection of the phase between the two carrier signals; the second modulation technique is a Space Vector Modulation specific for NPC inverters.

The main peculiarity of the proposed SVM consists on performing, in every operating condition, only commutation per phase during each sampling period. The comparison has shown that the proposed SVM always produces a smaller harmonics distortion.

\section{References}

[1]. P.Elangovan, Dr.C.Kumar, V.Suresh "Space Vector Modulation based Speed Control of Induction Motor Fed by Z-Source Inverter using PI controller"

[2]. Jih-Sheng Lai and Fang ZhengPeng, "Multilevel Converters- A New Breed of Power Converters" IEEE Trans. Ind. Electron., vol. 32, no. 3, pp. May/June 1996.

[3]. G. Mondal, K. Srivakumar, R. Ramachandra, K. Gopalkumar, and E. Levi, "A dual seven-level inverter supply for a an open-end winding induction motor drives,” IEEE Trans. Ind. Electron., vol. 56, no. 5, pp. 1665-1673, May 2009.

[4]. O. Lopez, J. Alvarez, J. Dovel-Gondoy, and F. D. Freijedo, "Multilevel multiphase space vector PWM algorithm," IEEE Trans. Ind. Electron., vol. 55, no. 5, pp. 1933-1942, May 2008.

[5]. Subrata K. Mondal, Joao O. P. Pinto and Bimal K. Bose, “ A Neural-Network-Based Space-Vector PWM Controller for a ThreeLevel Voltage-fed Inverter Induction mptor Drive”, IEEE Trans. Ind. Electron., vol. 38, no. 3, pp. May/June 2002.

[6]. Dongsheng Zhou (Medium Voltage Division/Rockwell Automation 6400W Enterprise/ Mequon, WI53092 USA) and Didier Rouaud (Siemens E \& A/Driver Division 100 Technology Dr. STE 102/Alpharetta, GA 30005), “ Experimental Comparisons of Space Vector Neutral Point Balancing Strategies for Three-Level Topology".

[7]. Dongsheng Zhou (Medium Voltage Division/Rockwell Automation 6400W Enterprise/ Mequon, WI53092 USA) and Didier Rouaud (Siemens E \& A/Driver Division 100 Technology Dr. STE 102/Alpharetta, GA 30005), “ Experimental Comparisons of Space Vector Neutral Point Balancing Strategies for Three-Level Topology

[8]. High Performance Control Of Ac Drives with MATLAB SIMULINK MODEL; Haitham Abu-Rub, Atif Iqbal, Jaroslaw Guzinski, Ed. 2012. Wiley Publications.

[9]. Generalised Theory of Electrical Machine; P.S Bhimbhra.

[10]. Advance Power Electronics and Ac Drives, Ned Mohan.

[11]. Power Electronics and Ac Drives; B.K Bose. 